\title{
Literature Review on the Impact of Education on Individual Income
}

\author{
Manxue Chen ${ }^{*}$ \\ School of Business \\ Northeast Normal University \\ P.R.China, 130117 \\ chenmx839@nenu.edu.cn
}

\author{
Kangyin Lu \\ School of Business \\ Northeast Normal University \\ P.R.China, 130117 \\ luky440@nenu.edu.cn
}

\author{
Chengcheng Tao \\ School of Business \\ Northeast Normal University \\ P.R.China, 130117 \\ 297939541@qq.com
}

\begin{abstract}
Since the 21st Century, the relationship between education and income, the trend of changes in the rate of return on education and the impact of the level of education on income gap have become hot issues in the field of labor economics and economics of education. Through sorting out the previous researches, this paper summarizes the relevant literature from four aspects which include related theories of education and income; the impact of education quantity on income; the different distribution of return to education and the impact of education quality on income, in order to provide reference and a new research point for the further research on return to education.
\end{abstract}

Keywords-Education quantity; Education quality; Return to education

\section{THE THEORY ABOUT THE RELATIONSHIP BETWEEN EDUCATION AND INDIVIDUAL INCOME}

The way where education affects the individual income is reflected in the direct increase of productivity, namely productive function; on the other hand, it is the signal function. Therefore, the theory of the influence of education on individual income includes two kinds of theories of human capital and educational signal.

\section{A. The human capital theory}

The human capital ideology originated from the prevailing period of classical political economy. In the works of classical political economists represented by Adam Simy and William Petty, they can see the sprout of the thought of human capital. From the beginning of the 1950s, economists began to regard human capital as an acquired investment of independent capital, rather than as a pure natural endowment. Some famous economist, including Theodore W. Schultz, Gary S. Becker and Jacob Mincer economists had made a series of groundbreaking research on the theory of human capital. As an important form of human capital accumulation and the principal means of human capital investment, the impact of education on personal income also gradually began to become important issues of labor economists. According to the theory of human capital, the effect of education on individual income is reflected in its productive function, that is, education can improve the labor productivity, and then increase the income level of the individual.

In 1964, in the "human capital", Becker used the cost benefit analysis to estimate different groups on profitability of education between University and high school in the First Half of 20th Century in the United States. The results showed that the higher the education level, the return to education was lower, and rates of return to education in the overall trend was up to human capital supply and demand conditions. The education difference was the most important factor for the individual income level. American economist Mincer toke the human capital theory as the foundation, respectively, and used the difference compensation model(Mincer,1958), accounting equation model(Mincer,1974), to deduce the Mincer wage income decision research models. It established the foundation of quantity to study the influence of human capital investment on income distribution.

\section{B. Educational signaling theory}

In the 1970s, Spence founded the labor market signaling model. He explained the information function of education, focusing on education as a kind of signal which has an impact on the labor market balance, and information asymmetry from the transmitted signal view. This triggered the dispute and discussion about the education function. The signaling theory of education explained the positive relationship between education and individual income from the information function of education. Spence(1973) and Stiglitz(1975) considered that the economic role of school education was the signal function. That is to say those people who improve labor productivity will be screened out, and the whole society will do the best. The signal function of education is reflected in the ability of the signal; on the other hand, it is also the labor force to enter the 
threshold of some high-income industries. Theory of educational signaling says that there are many factors affecting the individual labor productivity, so the education has little on the role. Education only can play to response to individual labor productivity. Namely under the asymmetric information in the labor market, employers generally believe that high educated employees with higher levels of productivity, which should earn relatively high wages. Thus education increases the signal to increase individual income.

\section{RESEARCH ON THE IMPACT OF THE EDUCATION QUANTITY ON INCOME}

On the micro study of the influence of education on individual income, scholars have mostly chosen the education quantity as a measure of educational factors.

According to the research of Psacharopoulos et al.(2004), since the beginning of the late 90s of the 20th century, the average level of developed countries(OECD) returns to education was $7.5 \%$, average level of return to education on Asian countries was 9.9\%, and the world was 9.7\%[1].

Since the end of the 1980s, scholars at home and abroad have begun to pay attention to the problem of the return to education in China, which was a measure of the education quantity as a measure of the level of education. The earliest estimates of the return to education in China were Jamison and Gaag(1987). They estimate the return to education with Huixian County in Gansu Province micro survey data through the Mincer Equation. The results show that in Chinese cities and towns, the return to education are at $4.7 \%$.

Shi L. and Wenbin L.(1994) used in 1988 the China Household Income Project data(CHIP) as the study sample, with least squares method to estimate the return to education in our country. They accessed return to education in urban areas was 3.8\%, and urban individual Rate of return was about two percentage points higher than in rural areas.

Zhang and Zhao(2002) used 1988-1999 China Health and Nutrition Survey data(CHNS), to estimate the return to education by least square method. They got the results for the 1988, 1994 and 1999, return to Education were respectively $4.7 \%, 7.8 \%$ and $11.5 \%$.

Shi L., Sai D.(2003) used in 1995 and 1999 CHIP data, with the OLS method to estimate the return to education. The results showed that the return to education showed an increasing trend; Rate of return on higher Education was higher than elementary Education.

Brauw and Rozelle(2004) used survey data in 2002 six Chinese provinces, employing the Hcekman choice model, to estimate the return to education. It turned out that education obtained a return of $6.4 \%$, young people, migrants and postprimary levels of education have higher returns on education[2].

Fleisher and Wang(2005) used 1994 retrospective sampling survey data as the study sample, employing 2SLS measurement method for empirical research. The results showed that before the Cultural Revolution, return to education showed a decreasing trend; and after the Cultural Revolution until the 1990s, the rate began to rise[3].
Xingxiang Z.(2012) used CHIP data in 2002 to estimate the rate of return on urban and rural education in china. The results showed that the gap between urban and rural education rate of return was 3.4\%. The difference between income and education returns under the common role of urban and rural areas in China may form education - income of the "Matthew effect".

Tao X.(2013) used the data in 2005 Chinese General Social Survey (CGSS), to estimate the characteristic of private education returns of our rural and urban. He found that China's return to education exist the phenomenon of increasing marginal benefit. This general trend was different to the international education general return; In addition, return to education exist "Matthew effect" between education level and income level.

\section{THE RETURN TO EDUCATION RESEARCH UNDER DIFFERENT INCOME DISTRIBUTION}

Carrying a large number of returns to education research to the education quantity as a proxy indicator of education, domestic and foreign scholars began to use quantile regression, income groups and the different income distribution of return to education in depth study. Most scholars are committed to the study of the difference of the return to education on different points using quantile regression method, in order to analyze how the conditional distribution of income varies with the change of education.

Knight and Song(2003), Bishop et al.(2005), Luo Chuliang(2007), respectively used CHIP data for empirical analysis. The results were basically consistent, and high-bit regression the low education rate of return was lower than the return position in the returns to education[4].

Chunbing X.(2006) used data from the CHNS data to make urban and rural investigation in 1991, 1993 and 1997 three years at different sites on the return to education situation. The results showed that high quantile regression of education return rate is lower than that of the low points in a regression return to education, but this situation from 1997 was no longer evident.

Mengtao G. and Yun H.(2006)'s results indicated that the quantile regression results show gender differences. For male labor group, the high quantile regression of return to education is lower than that of the low quantile regression, while woman is opposite.

Mengtao G. and Yang Y.(2006) used data of 8 provinces in East Central and western provinces to study the fixed point of observation. The results showed that the overall the high quantile regression of Rate to return was relatively high, and especially the samples that are in the junior high school and high school were the most obvious.

However, Chunbing X.(2008) argued that the simple use of sub quantile regression rates of return on education differences to study methodology of studying the impact of education on income gap was debatable; and, it is necessary to distinguish conditional distribution and the unconditional distribution in the application of quantile regression and reports the regression results. 
Zhifang S. and Jinghan C.(2010) used the 2006 CHNS data, based on the newly developed quantile regression method to make empirical analysis of the factors that affect the Chinese residents' educational return. It is found that optimal experience of residents in our country a few years quantile increased with the increasing trend; For each level of education, their return to education represented the decreasing trend when sites increased; The gender gap was largest in the lower quantile, and at higher quantile varies little; urban and rural gap with quantile rising and falling trend, especially in high site was not significant.

Lingzhi L., Yueyi H. and Yapeng W.(2013) took survey data in Hubei Province for empirical research by constructing a model of influencing factors and expanded investment in education Mincer income model. The study indicated widening of income gap emerged in China, and smooth differences in levels of return to education, but return on high Education was high and not be affected by it; different income levels of return to education showed significant difference: the middle-income group returns to education rate was the lowest, while lower income group was the highest.

\section{RESEARCH ON THE IMPACT OF THE EDUCATION QUALITY ON} INCOME

Some foreign scholars have examined the relationship between the education quality and individual income. Although these studies for education quality standards are not the same, but the results of this research show that education quality on the individual income exist certain influence. Morgan and Sirageldin(1968) first began to study the influence of the quality change of a particular educational project on the individual income change, which is the influence of the education quality on income[5]. The Review of Economics and Statistics published an album on educational quality issues in 1996.

Card and Krueger(1991) compiled three indicators of statistics 1915-1966 in 18 states of black and white schools to measure the education quality, to estimate labor returns to education from the southern part of the United States of different ethnic groups and state in 1960, 1970 and 1980. The study showed that the improvement of the quality of black education has a $20 \%$ explanation for the income gap between blacks and whites.

Altonji and Dunn(1996) used matching data samples to study the quality of school education through analysis of variance of individual income. Research suggested that the composite index such as teachers' pay, expenditure on education and education quality have significantly positive influence on the income of high school graduates[6].

Bratsberg and Terrell(2002)showed that after controlling per capita gross domestic product (GDP) and other factors remain unchanged, labors national immigration who come from student to teacher ratio low and high average education spending will get higher returns to education by 1980 and 1990 census data of the research results[7].

Domestic research on the quality of the education effect on income is not much. On the basis of human capital theory and the theory of social stratification, Liqiu Z.(2006) establish the form from the view of maximization of the personal utility. He also added the factors of regional housing rents and differences of the educational quality, and chose the OGM model to measure the impact of education inequality on income inequality. It is found that the difference in educational quality has a significant impact on the income difference. The difference of education quantity on non-east is not noticeable, but the difference in east is significant.

Guangqiang L., Dasong D. and Yu Q.(2013) used the provincial panel data from 2000 to 2008, and integrated the education quality into Mincerian earnings. The research results showed that the quantity and education quality have significant effect on income level of rural residents; in comparison, the income effect of education quality in eastern region is greater than the central and western regions. By contrast, the income effect of education quantity in central and western regions is greater than the other region[8].

Peng Z., Shi L.(2014) empirically studied educational returns of rural migrant workforce by using the 2005 National Bureau of Statistics sample survey of $1 \%$ of the population over the years as well as macro-related statistics. The results showed that the education quality can not only significantly affect income level of the migrant workers who are not college students, but also significantly affect the marginal returns of quantitiy education.

\section{CONCLUSION}

From the above review it is not difficult to see that the impact of education to income goes without saying. In the research about the economic value of education, most of the scholars tend to take the education quantity as the research focus. However, the research for characteristics of education quantity and income return as well as difference comparison under different distribution are not the same. This is due to the difference of sample selection and research methods, in part due to the influence of educational quality on the income effect of education quantity. That is to say, to produce an additional year of education in different regions of the same level of human capital may not be equivalent (Behrman \&Birdsall, 1983; Hanushek \&Wobmann, 2007). On the basis of previous studies of scholars at home and abroad, we should seek for further study on the education quality on the mechanism of individual income and income inequality degree of interpretation, to fully explore the mechanism of education on the individual income.

\section{REFERENCES}

[1] Psacharopoulos G, Patrinos* H A. Returns to investment in education: a further update[J]. Education economics, 2004, 12(2): 111-134.

[2] De Brauw A, Rozelle S. Reconciling the returns to education in rural China[J]. Unpublished paper dates March, 2004, 12: 2004.

[3] Fleisher B M, Wang X. Returns to schooling in China under planning and reform[J]. Journal of Comparative Economics, 2005, 33(2): 265-277.

[4] Knight J, Song L. Increasing urban wage inequality in China[J]. Economics of Transition, 2003, 11(4): 597-619.

[5] Morgan J, Sirageldin I. A note on the quality dimension in education[J]. The Journal of Political Economy, 1968: 1069-1077. 
[6] Altonji J G, Dunn T A. Using siblings to estimate the effect of school quality on wages[J]. The Review of Economics and Statistics, 1996: 665-671.

[7] Bratsberg B, Terrell D. School quality and returns to education of US immigrants[J]. Economic Inquiry, 2002, 40(2): 177-198.
[8] Guangqiang L., Dasong D. and Yu Q. The Impact of Education Quantity and Education Quality on Rural Residents' Income-Based on the Empirical Analysis of Provincial Panel Data[J]. Educational Research, 2013, 05:20-29. (In Chinese) 